\title{
EJSBS
}

The European Journal of Social \&

Behavioural Science

ISSN: 2301.2218 (ONUNE)
OPEN ACCESS

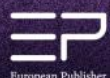

The European Journal of Social and Behavioural Sciences

EJSBS Volume XXX, Issue II (eISSN: 2301-2218)

\section{THE DEVELOPMENT OF ARTIQUE - INDEPENDENT ARTISTS AND ONLINE ART CRITICISM}

\author{
Nor Suliana Mak Mona, Siti Zuraida Maaruf ${ }^{b *}$, \\ Akmal Ahamed Kamal ${ }^{\mathrm{c}}$ \\ ${ }^{a}$ Sekolah Menengah Islam Al-Amin, Gombak, Selangor, Malaysia,norsulianamakmon@gmail.com \\ ${ }^{b}$ Universiti Teknologi MARA (UiTM), Selangor, Malaysia, sitiz610@uitm.edu.my \\ ${ }^{c}$ Universiti Teknologi MARA (UiTM), Selangor, Malaysia, akmal@uitm.edu.my
}

\begin{abstract}
Learning art online breaks the geographical barriers and frontiers between art students, artists, galleries, and museums. Studio critique can now be performed beyond the brick walls of a physical room through the virtual platform. This research studies on the impact of art criticism in an online gallery for independent artists which was developed through the design and development method (DDR) while Visual Culture Model was employed for Phase One in the Needs Analysis. The positive feedback obtained from five independent artists who participated in the research revealed that it is common for artists to use social networking sites as avenues for art criticism. The use of social networking sites is common among artists and regarded as valuable in their field. The respondents are supportive in the development of an online group for art criticism that could fortify their creativity and ultimately their artworks. Hence, the findings of the interview suggest that a social networking site like ARTIQUE would be a progressive platform for artists' professional development.
\end{abstract}

Keywords: Social media, social networking site, art criticism, online gallery

(C) 2021 Published by European Publisher. www.europeanpublisher.com

${ }^{*}$ Corresponding author. Tel.: +6017-6525400

E-mail address: sitiz610@uitm.edu.my

doi: $10.15405 /$ ejsbs.293

This work is licensed under a Creative Commons Attribution-NonCommercial-NoDerivatives 4.0 International License. 
https://doi.org/10.15405/ejsbs.293

eISSN: 2301-2218 / Corresponding Author: Siti Zuraida Maaruf

Selection \& Peer-review under responsibility of the Editors

\section{Introduction}

Online networking has overcome communication barriers globally. The expansion of Social Network Services (SNS) with its technological progression has spearheaded new economic activities and quests for future possibilities in trading with other industries. Interestingly, SNS has allowed for video conferences and broadcasts that encourages prompt meetings and discussions which is becoming conversant in the field of Arts. Aifan (2015) has highlighted that SNS has opened a wider horizon for teaching and learning by accommodating various activities that encourage sharing and transferring of data and disclosing self-reflections that may lead to constructive dialogues. More significantly, social media may embrace more extensive variety of structures that include social blogs, internet gatherings, weblogs, WIKIs, micro blogging, videos, podcasts, pictures, ratings, and social bookmarking. Some of the platforms that are widely used include YouTube, Facebook, Twitter, Flickr, Digg, and Blogger. These are among the numerous platforms available for social networking that not only improve but further enhance the development of ideological and innovative establishments like Web 2.0 and the expansion of User-Generated Content (Kaplan \& Haenlein, 2010). Online platforms are now growing to serve various purposes in the field of Arts including the area of art criticism that was long ensconced within the cocoon of physical studios or galleries. The premise that information and communication technologies are complementary to the study of Art has been established by researchers like Mirzoeff (1999) who posited that art can be studied via the internet.

\section{Background of the Study}

This study aims to stimulate our comprehension on how social media platforms support online art criticism by developing an e-portfolio platform. Barret (2006) suggests that eportfolio serves as a medium of reflection that can improve students' understanding of their own learning while expanding their horizon towards their art by archiving their personal artistic development. The internet platform may be used in a formal educational setting; however, this platform serves as an underpinning for personal development when Arts students or even professionals alike to document their artistic journeys for a specific project and their holistic development (Gray, 2008). Subsequently, the ability to view the criticisms of one's arts could be a motivational factor for personal growth (Hussain et al., 2011). This is supported by Syamsul Nor Azlan et al. (2016) who state that the e-portfolio is valuable especially when reflecting on longitudinal artistic development. A prior study by Barret (2006) had established that using technology encourages students and artists alike to keep updates of their works because of its ease of management and storage especially when these platforms are free with 
https://doi.org/10.15405/ejsbs.293

eISSN: 2301-2218 / Corresponding Author: Siti Zuraida Maaruf

Selection \& Peer-review under responsibility of the Editors

unlimited storage like DeviantArt, Facebook, Pinterest, and blogs, while others can provide their comments and criticism. Free and unlimited storage platforms allow students who are budding artists to share their thoughts and art processes that are open for the input and opinions from those who see or follow their work. Although various studies have investigated the benefits of using online platforms for Art Criticism, further research that investigate the opinions from teachers or trainers would complement current information available within the area of Arts education.

\section{Problem Statement}

Several Malaysia-based online gallery platforms have been developed to encourage Malaysian artists from various backgrounds to share their artwork with others such as Alyssa Gallery, Art Malaysia, Malaysia Artist, Art Square, and G13 Gallery. These online galleries have been instrumental in promoting various artwork from Malaysian artists and to sell their work. Artists are able to earn substantial amounts through these online galleries that can reach buyers around the globe. However, many of the online platforms available lack the channel for art criticism which is crucial for budding artists who need input regarding their artwork. Therefore, this study aims to develop a new online platform for art criticism while allowing artists to publish their work.

It is very common for art students to have their art critique sessions within the walls of their school art studios in the presence of lecturers, artists, and classmates. Dray (2014) had observed that the common practice by art faculties is to display students' works in bulletin boards, display cabinets, or art shows within the faculty spaces but such displays lack the opportunities for observers to provide their criticisms on the artwork. However, this drawback could be surmounted if the artists share their artwork in online platforms (Aifan, 2015) and this is clearly visible with the presence of social media platforms such as Facebook and Instagram. Hence, this study attempts to identify how Malaysian artists could use social media platforms to showcase their work and to attain substantiated criticisms of their artwork. Importantly, this would also provide them with the opportunity to get the exposure and experience needed through sharing with the art community beyond geographical borders. Social media platforms can be optimised as a learning ground for the development of their artistic skill and personal growth. Therefore, this study is essential to obtain graduate artists' accounts in using an online gallery platform for art criticism. 
https://doi.org/10.15405/ejsbs.293

eISSN: 2301-2218 / Corresponding Author: Siti Zuraida Maaruf

Selection \& Peer-review under responsibility of the Editors

\section{Research Objectives}

The present study seeks to:

4.1 investigate independent artists' opinions about online art criticism

4.2 obtain independent artists' consensus to join an online platform to promote their artwork.

4.3 obtain independent artists' consensus preference on the social networking platform that they prefer.

\section{Methodology}

The Design and Develop Method (Richey \& Klein, 2007) was applied as the research design focussing on the development of an online gallery called Artique as a virtual platform for art criticism to promote independent artists' work. The Design and Development method is a systematic and consistent process in design to develop and evaluate products and processes for internal effectiveness. It comprises three phases that the researcher needs to complete; phase one is the need analysis; phase two is the development and design; and phase three is the implementation and evaluation. Although the whole research comprises three phases with specific procedures, this paper reports only the Needs Analysis performed in Phase 1 as the authors felt that the needs analysis sets the stage for an overview of the development and implementation processes of Artique. In other words, this paper provides the raison d'etre for the need to develop Artique as a possible avenue for art criticism.

A summary of the first phase on the development of Artique is depicted in Figure 1.
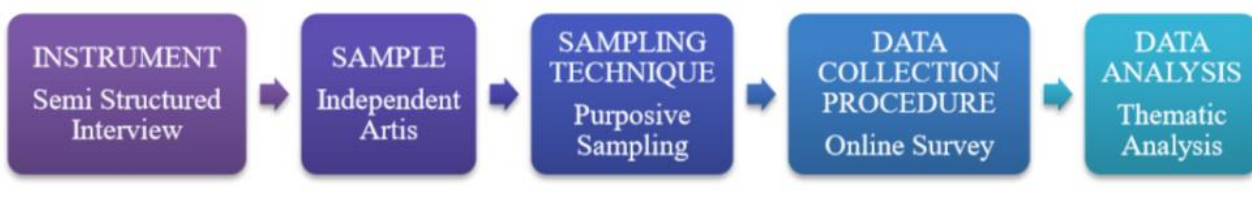

Figure 1. A Summary of the Research Design for Phase 1: Need Analysis

\subsection{Research Instrument}

The first procedure in Phase 1 involved the use of a semi-structured interview with the identified respondents to obtain qualitative data necessary for the research and to fulfil the research objectives as suggested by DiCicco-Bloom and Crabtree (2006). The interview involved five independent artists with backgrounds in Art and Design. The interview was 
https://doi.org/10.15405/ejsbs.293

eISSN: 2301-2218 / Corresponding Author: Siti Zuraida Maaruf

Selection \& Peer-review under responsibility of the Editors

conducted individually in an informal manner, but the protocols for each interview were maintained.

\subsection{Research Participants}

This study applied the purposive sampling technique which is one of the most common sampling strategies for an identified group of participants according to preselected criteria relevant to the research (Zainuddin, 2015). The samples were five independent artists comprising two female and three male artists who were Art and Design graduates. The five respondents were representative of independent artists who have knowledge and experience in art critique and exhibition and are between 26 and 27 years old. They are also fulltime or parttime artists who are active in producing artwork.

\subsection{Data Collection Procedure and analysis}

A semi-structured interview was conducted with the five participating artists revolving around their opinions of online art criticism. According De Carlo (2018),

"Interviews are an excellent way to gather detailed information. They also have an advantage over surveys, as they can be adapted as you learn more information...In an interview, however, you can follow up on new and unexpected topics that emerge during the conversation. Trusting in emergence and learning from your participants are hallmarks of qualitative research. In this way, interviews are a useful method to employ when you want to know the story behind the responses" (n.p.)

This rationale fits well with the premise of this research as the researchers' aim was to elicit insights into the participants' decision-making process regarding their choices and preferences on platforms for art criticism.

Prior to the interview, the participants were briefed on the objectives of the study, its rationale, and some information that the researcher had gathered with regard to online gallery and art criticism. All responses were documented, transcribed, and organized in the form of thematic analysis to obtain unblemished data with discernible themes or patterns (Braun \& Clarke, 2006).

\section{Findings and Discussions}

In this section, the findings of the semi-structured interview are presented and discussed. The identification markers refer to $\mathrm{R}$ for respondent, followed by the number 
https://doi.org/10.15405/ejsbs.293

eISSN: 2301-2218 / Corresponding Author: Siti Zuraida Maaruf

Selection \& Peer-review under responsibility of the Editors

indicating the sequence of the respondents. $\mathrm{L}$ followed by a number refers to the line of the dialogue transcribed during the course of the interview.

\subsection{Respondents' opinions on online art criticism to discuss artwork}

Four of the independent artists agreed that online art criticism is beneficial for artists to discuss their work as it may be used constructively to develop and improve not only their skills but also knowledge of art. Two respondents had highlighted that online art criticism platforms are advantageous as they are not limited to space and time while discussions can take for an infinite duration. Not only that, the discussions are also stored in the platform and can be revisited by anyone using the platform as mentioned by Respondent 4; “...the biggest advantage is no one is tied up to a certain time, the discussion can last for a long time. Even if a person missed the live discussion, they could still view the post and read previous discussions..." (R4:L15). Addressing its selling potential, two respondents opined that the online platform can be used as a marketing outlet to sell independent artists' works. Nevertheless, one respondent felt that independent artists should first get their words displayed in a gallery to gain public recognition and criticism. For whatever it is worth, online platforms could still be a place that can provide constructive feedback useful for the artists' development.

Online criticism can provide positive insights for the artists to develop and improve their knowledge and skills. Respondent 1 opined that “...opinions and criticisms from someone of various backgrounds can give an effective impact on the artists" (R1:L113), which when taken with an open mind, the artists can revisit and reanalyse various criticisms posted on the platform. Respondent 4 concurred that any comments which were missed could be revisited at any point of time after they were posted. Respondents 3, 4 and 5 highlighted that online art criticism opens the setting beyond the gallery walls reaching out to various countries allowing multinational exposure to the artist through online discussions. However, Respondent 3 cautioned that any artist who is up for such an experience would need to pluck up their courage when put in such an open spot. The respondent believes that "...the artist should not have to play safe; they should receive a feedback whether it was positive or vice versa” (R3:L1-6). This is because although some criticisms are constructive, they can come out strong.

Although Respondent 2 agreed with the benefits of using online platforms in art criticism, he still believed it is still essential for artists to get their introduction in an art gallery. Believing that “... both ways work well together” (R2:L15), artists would still require that "real life' experiences where art enthusiasts could get that sense of seeing and feeling the artworks and getting more in-person with the creator. Importantly, Respondent 3 highlighted that the online platform could still provide "a lot of information about particular artworks and how 
https://doi.org/10.15405/ejsbs.293

eISSN: 2301-2218 / Corresponding Author: Siti Zuraida Maaruf

Selection \& Peer-review under responsibility of the Editors

the artists manifest the idea, how the artist works and receives feedback," (R3:L1-6).

Therefore, artists could still gain multiple benefits from using online platforms while opening the doors for them to get recognized in order to get a spot in art galleries and exhibitions.

\subsection{Respondents' acceptance of an online gallery for art criticism}

Four of the respondents concur to using online platforms as an avenue to provide art criticism and discuss about artwork; but one respondent had some hesitations to this idea. Respondent 3 felt that artists need to have 'real' art gallery experience as an industry requirement; “Technically, I think ... in industry's requirement, I would say no for the online platform or any platform which gathers the artist altogether. To develop the career efficiently, the artist himself has to communicate and create a bond in a community" (R3:L7-17). The respondent further elaborated that " $a$ visual artist should be interpreted visually and live... the artist can move, can communicate freely with the other artists, with galleries' executives". Importantly, Respondent 3 believes that "students should not publish their artworks online; instead, they should seek advice from teachers or lecturers to develop their skills. But if they want a compliment or advice from public, it was not wrong at all" R3:L7-17). Although the respondent approves about aspiring artists getting online opinions from the public, he persisted in his stance that artists should communicate face-to-face with the general public, other artists, and the gallery team. With that, the respondent insists that real-life interaction with others would “...create a bond locally and internationally" suggesting that the artists have better chances at selling their artwork.

Respondents 1 and 4 pointed out that one of the major advantages of an online gallery is that it provides a space for exchange of ideas and experiences. While agreeing to the use of an online gallery, Respondent 1 also added that; "Well... I agree if any grouping of art criticism. So here we can see people who are alert and attentive to the arts who can not only convey ideas but also exchange opinions, experiences, and life as an artist. More or less, they can explain their understanding of a discussion of art. Artists, audience and collectors can communicate directly online" (R1:L13-18) (R4:L11-14:T). He finds that an online gallery would be instrumental for aspiring artists as they could communicate directly with everyone related to the arts industry this way. Meanwhile, Respondent 4 added that "It would be nice if someone with knowledge on art criticism like senior artists, gallery curators or art lecturers in that group can give their opinions and suggestions to produce good quality artwork, since we can browse the internet on our Smartphone anywhere and anytime." (R4:L11-14). Respondent 5 offered a reminder that the use of current technology which facilitates communication has paved the way for promising artists to learn from their long-established 
https://doi.org/10.15405/ejsbs.293

eISSN: 2301-2218 / Corresponding Author: Siti Zuraida Maaruf

Selection \& Peer-review under responsibility of the Editors

counterparts. This opinion was also mirrored by Respondent 5 who believes that "It is a great opportunity for local artists to participate in an online platform...from what I see, other countries have already been using virtual platforms for a long time... they are able to promote their artwork all over the world and I am following a few websites that publish artwork" (R5:L513). She admitted following a few online platforms that publish artworks from various artists such as 'Artemis' and 'Artelier Gallery'.

\subsection{Respondents' interest in participating in online platforms to promote artwork}

Three respondents displayed their interest in participating in online platforms to promote artwork. One of them said that any given opportunities to promote their artwork and become a well-known artist must be fully utilized. In contrast, two respondents were not interested in joining any group but they did want to exhibit their artwork virtually. Respondent 1 stated that, "Of course, I want to participate. I have a lot of work to display but there is no chance." (R1:L18-19). Respondent 5 also admitted that he would join online platforms that would publish his works. Respondent 4 meanwhile felt “...we should grab all the chances ... who knows one day it would be our chance to become one of the well-known artists in Malaysia.” (R4:L14-15). Regardless, Respondent 2 stated “...prefer exhibit outside not online” (R2:L12), which is also mirrored by Respondent 3 “...don't like to join any online group and published my artwork online. It is really subjective depends on the individual" (R3:L18-26). He leaves it to individual preferences in choosing their platforms to display their artwork. However, Respondent 3 admitted that the online platform has its advantages in the long-term saying that "it is good for long term career development, we might compare this with another solution, gallery promotion and curatorship." This is because an online platform could store uploaded photos of artwork for as long as the platform is available. Not only that, people can also revisit the platform at any time and not be restricted by geographical barriers.

\subsection{Respondents' preference of social networking sites to display their artwork}

Although there are many online platforms that allow artists to share their artwork hassle free, all the respondents prefer using Facebook as the online platform to share their artworks. Also, they believe that Facebook users could easily find them through its search algorithm. Respondent 1 stated that, "If we use Facebook maybe much better because everyone can see right. Especially to see how many people like or see our works and react or give comment about it.." (R1:L20-22:T:9.52p.m:019/05/2016). Respondent 2 revealed "It is just okay to use Facebook because there are many people in there..." (R2:L13:T:2.50p.m:17/05/2016). Meanwhile, Respondent 3 simply responded, "Can just use Facebook.." 
https://doi.org/10.15405/ejsbs.293

eISSN: 2301-2218 / Corresponding Author: Siti Zuraida Maaruf

Selection \& Peer-review under responsibility of the Editors

(R3:L27:T:4.44p.m:17/05/2016). Also, Respondent 4 considers that using "Facebook is the easiest and simple for people to see and comment.." (R4:L15:T:3.09p.m:22/05/2016). Respondent 5 revealed the strength of groups in Facebook in reaching out to various individuals who may not be in the artist's personal network, "Yeah okay.. and I think there are many groups in Facebook.." (R5:L15:T:8.23p.m:25/05/2016). With Facebook's group utility, users can join various groups that could further promote artists' work to various audiences aside from only individual connections. Ultimately, the use of online social media platforms such as Facebook prepares the ground for aspiring artists to get noticed for their artistic work and talent.

\section{Conclusion and Implications}

The findings describe independent artists' opinions on the need for an online gallery for art criticism and their interest to participate in one. The majority of the respondents agreed that an online gallery for art criticism is a good platform to discuss artwork. Three of the five respondents also stated that art criticism in an online gallery is a good platform to exchange ideas, criticism. Such a platform would provide the opportunity for the artistic community and other stakeholders to interact. Besides that, they agreed that such a platform for art criticism can broaden and improve artwork through the feedback or critique given. This platform would be a forum for students and artists to help one another to improve and provide perspectives that are beneficial for their growth (Frost, 2019). Two of the respondents had also mentioned that an online gallery is a good marketing channel to attract collectors and galleries while setting the ground for art criticism to discuss artwork. They stated that an online gallery for art criticism generates many advantages such as encouraging an exchange of ideas, opinions, and suggestions for artists to improve their artistic knowledge and skills. The communication that occurs in SNS sited could build and shape educational goals and while simultaneously encouraging individual communication (Kord, 2008). Maaruf, et al.'s (2020) study demonstrated the advantages of having an online gallery for art criticism for independent artists, students, and art collectors.

Additionally, the respondents also mentioned that online platform allows young artists, senior artists, curators, art lecturers, and the audience to communicate directly with each other without physical limitations. An online art platform is a powerful space for publishing artwork for viewers who are not familiar with art especially the younger generation (Jung, 2013). The majority of the respondents stated that they would participate in an online platform to promote their artwork as it is a good opportunity to get noticed. However, two respondents had reservations about online platforms. They suggested that artists need the experience of 
https://doi.org/10.15405/ejsbs.293

eISSN: 2301-2218 / Corresponding Author: Siti Zuraida Maaruf

Selection \& Peer-review under responsibility of the Editors

exhibiting their works in physical sites and gain experience before publishing their artwork in any online platform. Given the choice, all the respondents picked Facebook as their preferred online gallery for art criticism, stating that Facebook facilitates connections and participation. Research has established that Facebook is currently the most popular social networking site (Holland \& Tiggemann, 2016). This is supported by Aydin (2012) and Wang and Mark (2018) who found that Facebook users are mostly college students.

The paper reported the findings of the first phase of the 3-phase study, which focused on the perceptions of artists on the possibility of utilising an online platform to critique artwork. The findings are generally promising for the development of an online platform for the purpose of promoting more dialogue among the art community.

\section{Acknowledgements}

The author(s) declare that there is no conflict of interest.

\section{References}

Aifan, H. A. (2015). Saudi students' attitudes toward using social media to support learning. ProQuest Dissertations \& Theses Global. (Order No. 3713504)

Aydin, S. (2012). A Review of Research on Facebook as an Educational Environment. Educational Technology Research and Development, 60(6), 1093-1106.

Barrett, H. C. (2006). Researching and Evaluating Digital Storytelling as a Deep Learning Tool. Electronic Portfolios. https://electronicportfolios.com/SITEStorytelling2006.pdf

Braun, V., \& Clarke, V. (2006). Using thematic analysis in psychology. Qualitative Research in Psychology, 3(2), 77-101. https://doi.org/10.1191/1478088706qp063oa

DeCarlo, M. (2018). Scientific inquiry in Social Work. Open Social Work education. https://scientificinquiryinsocialwork.pressbooks.com/\#main

Dray, E. (2014). The Use of Technology to Display Student Artwork. Unpublished masters thesis, West Virginia University. https://researchrepository.wvu.edu/cgi/viewcontent .cgi? article $=1593 \&$ context $=$ etd

Frost, C. (2019). Digital Critics: The Early History of Online Art Criticism. Leonardo, 52(1), 37-43. https://doi.org/10.1162/leon_a_01379

Gray, L. (2008). Effective practice with e-portfolios. http://www.jisc.ac.uk/media/documents/ publications/effectivepracticeeportfolios.pdf

Harden, G. (n.d.). A Comparative Analysis of Social Networking Site Use in Two Distinct Cultures: Evaluating the IT-Culture Conflict | Open Access Journals. Global Media Journal. Retrieved on April 24, 2019, from https://www.globalmediajournal.com/ open-access/a-comparative-analysis-of-social-networking-site-use-in-two-distinctcultures-evaluating-the-itculture-conflict.php?aid=35900

Hussain, M. A., Mehmood, A., \& Sultana, M. (2011). An Inquiry into Benefits of Reflective Practice in Open and Distance Learning. Turkish Online Journal of Distance Education, 12(2), 51-59. https://eric.ed.gov/?id=EJ964960 
Holland, G., \& Tiggemann, M. (2016). A systematic review of the impact of the use of social networking sites on body image and disordered eating outcomes. Body Image, 17, 100-110. https://doi.org/10.1016/j.bodyim.2016.02.008

Kaplan, A. M., \& Haenlein, M. (2010). Users of The World, Unite! The Challenges and Opportunities of Social Media. Business Horizons, 53(1), 59-68. https://doi.org/10.1016/j.bushor.2009.09.003

Kord, J. I. (2008). Understanding the Facebook Generation: A study of the relationship between online social networking and academic and social integration and intentions to re-enroll | Semantic Scholar.

Maaruf, S. Z., Mon, N. S. M., \& Supramaniam, K. (2020). ARTIQUE: An Art Criticism Session through Online Gallery for Independent Artists. International Journal of Academic Research in Business and Social Sciences, 10(14), 102-113. https://doi.org/10.6007/IJARBSS/v10-i14/7367

Mirzoeff, N. (Ed.) (1998/2002) Visual Culture Reader. Routledge.

Mirzoeff, N. (Ed.) (1999) Diaspora and Visual Culture: Representing Africans and Jews. Routledge.

Mohamad, S. N. A., Embi, M. A., \& Nordin, N. M. (2016). Designing e-portfolio with ARCS motivational design strategies to enhance selfdirected learning. Higher Education Studies, 6(4), 138. https://doi.org/10.5539/hes.v6n4p138

Richey, R. C., \& Klein, J. D. (2007). Design and Development Research: Methods, Strategies, and Issues. Lawrence Erlbaum Associates, Inc.

Wang, Y., \& Mark, G. (2018). The Context of College Students' Facebook Use and Academic Performance. Proceedings of the 2018 CHI Conference on Human Factors in Computing Systems, 1-5. https://doi.org/10.1145/3173574.3173992

Zainudin, A. (2015). Research Methodology and Data Analysis (2nd Ed.). Penerbitan Press Universiti Teknologi Mara. 